\title{
《渔业科学进展》编辑委员会
}

\section{THE EDITORIAL BOARD OF PROGRESS IN FISHERY SCIENCES}

主任委员 Chairman 唐启升 TANG Qisheng

副主任委员 Vice-Chairman 麦康森 MAI Kangsen 桂建芳 GUI Jianfang 金显仕 JIN Xianshi

委 员 Editorial Committee (以姓名笔画为序)

$\begin{array}{llll}\text { 王清印 WANG Qingyin } & \text { 王鲁民 WANG Lumin } & \text { 王新鸣 WANG Xinming } & \text { 戈贤平 GE Xianping } \\ \text { 孔 杰 KONG Jie } & \text { 包振民 BAO Zhenmin } & \text { 曲克明 QU Keming } & \text { 任胜民 (新西兰)REN Shengmin } \\ \text { 危起伟 WEI Qiwei } & \text { 庄 平 ZHUANG Ping } & \text { 刘英杰 LIU Yingjie } & \text { 关长涛 GUAN Changtao } \\ \text { 江世贵 JIANG Shigui } & \text { 严小军 YAN Xiaojun } & \text { 李 健 LI Jian } & \text { 李 军 (美国)LI Jun } \\ \text { 李来好 LI Laihao } & \text { 李家乐 LI Jiale } & \text { 李 琪 LI Qi } & \text { 杨红生 YANG Hongsheng } \\ \text { 肖 放 XIAO Fang } & \text { 何建国 HE Jianguo } & \text { 邹桂伟 ZOU Guiwei } & \text { 宋林生 SONG Linsheng } \\ \text { 张士璀 ZHANG Shicui } & \text { 张国范 ZHANG Guofan } & \text { 陈松林 CHEN Songlin } & \text { 陈 勇 (美国)CHEN Yong } \\ \text { 林 洪 LIN Hong } & \text { 岳根华 (新加坡)YUE Genhua } & \text { 周永灿 ZHOU Yongcan } & \text { 赵宪勇 ZHAO Xianyong } \\ \text { 俞志明 YU Zhiming } & \text { 秦 松 QIN Song } & \text { 秦启伟 QIN Qiwei } & \text { 徐 跑 XU Pao } \\ \text { 徐 皓 XU Hao } & \text { 黄 倢 HUANG Jie } & \text { 常亚青 CHANG Yaqing } & \text { 常剑波 CHANG Jianbo } \\ \text { 崔利锋 CUI Lifeng } & \text { 解绶启 XIE Shouqi } & \text { 翟毓秀 ZHAI Yuxiu } & \text { 薜长湖 XUE Changhu }\end{array}$

主编 Editor-in-Chief 金显仕 JIN Xianshi

副 主 编 Associate Editor-in-Chief 李 健 LI Jian 孔 杰 KONG Jie

编辑部主任 Editorial Director 常 青 CHANG Qing

渔业科学进展

YUYE KEXUE JINZHAN

（双月刊，1980年创刊）

\section{PROGRESS IN FISHERY SCIENCES}

( Bimonthly, founded in 1980 )

第 41 卷 第6 期 2020 年 12 月

Vol.41 No.6 Dec. 2020

\begin{tabular}{|c|c|c|c|}
\hline 主管单位 & 中华人民共和国农业农村部 & Administrated & y Ministry of Agriculture and Rural Affairs,P.R.China \\
\hline 主办单位 & $\begin{array}{l}\text { 中国水产科学研究院黄海水产研究所 } \\
\text { 中国水产学会 }\end{array}$ & Sponsored & $\begin{array}{l}\text { Yellow Sea Fisheries Research Institute, } \\
\text { Chinese Academy of Fishery Sciences }\end{array}$ \\
\hline 出版单位 & $\begin{array}{l}\text { 科 学出版 社 } \\
\text { 地址: 北京乐黄城根北街16号, 邮编: } 100717\end{array}$ & Published & $\begin{array}{l}\text { China Society of Fisheries } \\
\text { y Science Press }\end{array}$ \\
\hline 编辑单位 & 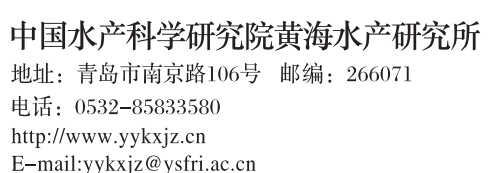 & Edited & $\begin{array}{l}\text { Add:16 Donghuangchenggen North Street, Beijing 100717, China } \\
\text { Yellow Sea Fisheries Research Institute, } \\
\text { Chinese Academy of Fishery Sciences } \\
\text { Add:106 Nanjing Road,Qingdao,266071,China; Tel: 0532-85833580 } \\
\text { http://www.yykjjz.cn; E-mail:yykjiz@ ysfri.ac..cn }\end{array}$ \\
\hline 编 & 金显仕 & Editor-in-Chief & Jin Xianshi \\
\hline 刷 & 青岛国彩印刷股份有限公司 & Printed & y Qingdao Guocai Printing Co.,Ltd. \\
\hline 国内发行 & 中国邮政集团公司山东省分公司 & Domestic Distributed by & y China Post Group Corporation Shandong Branch \\
\hline $\begin{array}{l}\text { 订 购 } \\
\text { 国外发行 }\end{array}$ & $\begin{array}{l}\text { 全国各地邮政局 } \\
\text { 中国国际图书贸易总公司 } \\
\text { 地址: 北京399信暞 邮编: } 100044\end{array}$ & $\begin{array}{l}\text { Subscription } \\
\text { Overseas Distributed by }\end{array}$ & $\begin{array}{l}\text { Post Offices All Over China } \\
\text { y China International Book Trading } \\
\text { Corporation } \\
\text { P.O.Box 399, Beijing 100044, China }\end{array}$ \\
\hline
\end{tabular}

中国标准刊号

ISSN 2095-9869

CN $37-1466 / \mathrm{S}$
国内邮发代号：24-153

国外发行代号：4578Q

国内外公开发行
I S SN 2095-9869

定 价：40.00元

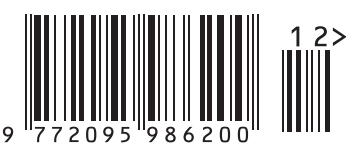

